\title{
EDITORIAL
}

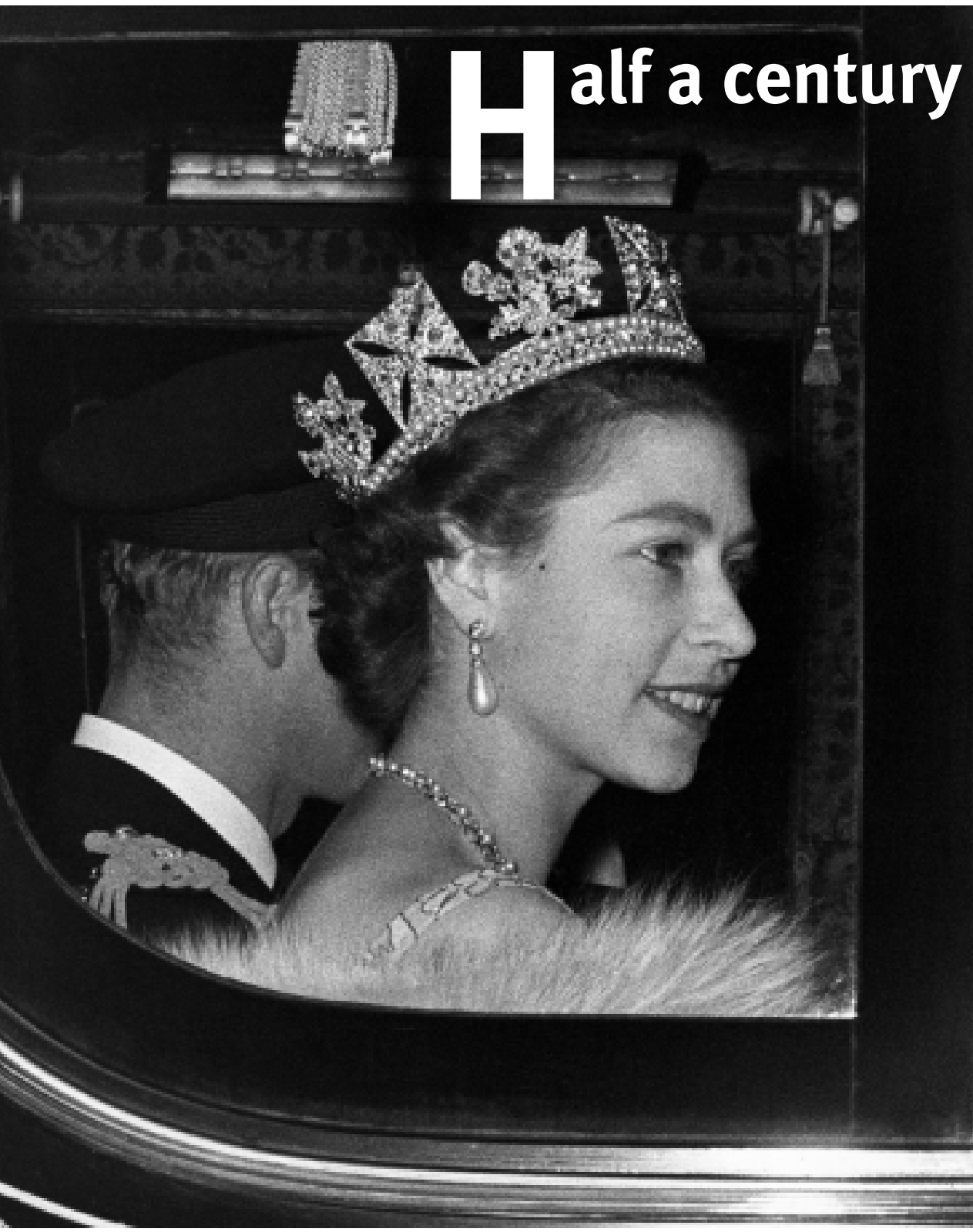

Queen Elizabeth II of the United Kingdom and the Commonwealth, Coronation, 1953

Jeremy Farrar

Centre for Tropical Diseases, 190 Ben Ham Tu, Quan 5, Ho Chi Minh, Vietnam; Email: jeremyjf@hcm.vnn.vn Practical Neurology, 2002, 2, 188-191

\section{JUNE 1952}

Princess Elizabeth ascends to the British throne, Winston Churchill is the British Prime Minister, Newcastle win the FA Cup, ration books are still in use and a pint of beer costs 3p. In the USA, Eisenhower (with Nixon as Vice President) wins the Presidential Election, the Invisible Man is the best seller, and the New York Yankees win the World Series. Selman Waksman is awarded the Nobel Prize for Medicine for his role in the discovery of Streptomycin. Following a coup, King Farouk is ousted as King of Egypt. Two consultant physicians are appointed; Dr Mandela to a hospital in Central Africa and Dr Joseph Bloggs to a London teaching hospital. Their first consultant ward rounds are conducted with a mixture of nervous excitement and trepidation. The first five patients Dr Mandela sees have just been admitted and are suffering from cerebral malaria, TB meningitis, tetanus, epilepsy and rabies. The first patient he treats with quinine, the second patient with streptomycin and is very excited to be able to add the recently available isoniazid for the first time. The patient with tetanus receives equine antitoxin and penicillin, the fourth patient phenobarbitone and the last patient is given intramuscular diazepam and discharged home to his family for terminal care. Joseph Bloggs's ward round in the Victoria Infirmary, London is a little different. The first patient has ischaemic chest pain, the second has had a transient ischaemic attack, the third Guillain-Barré Syndrome, the fourth patient has had her second episode of optic neuritis in the last year and the last patient has intractable temporal lobe epilepsy. Dr Bloggs prescribes diazepam for the first patient and insists he remain on in-hos- 


\section{tion of Queen Elizabeth II: but more to be done in the developing world}

pital bed rest for 6 weeks with no visitors for the first 2 weeks. Dr Bloggs is particularly excited to discover the second patient has a subtle speech problem (which had escaped the junior doctor) that he ascribes to a lesion just posterolateral to the third frontal convolution of the left cerebral hemisphere. He reassured the attending junior staff that he had presented a case such as this at Queen Square and bed rest and a small dose of phenobarbitone were the obvious treatment. The lady with Guillain-Barré Syndrome was ordered to rest, and the patient with optic neuritis was prescribed vitamins and told she was probably over-tired but would make a full recovery and had nothing to worry about. Intramuscular phenobarbitone was given to the young girl with temporal lobe epilepsy and diazepam to her mother who created quite a scene.

\section{JULY 2002}

By chance, both Dr Mandela and Dr Bloggs's grandchildren followed in their esteemed footsteps, became physicians and started their new consultant appointments on the same day in 2002. Queen Elizabeth was still on the British throne having just celebrated her Golden Jubilee, Tony Blair was Prime Minister, and Arsenal won the FA Cup. Dr Mandela Jr. starts on the same ward his grandfather had started in and sees a similar group of patients to his grandfather 50 years earlier. The first five patients have cerebral malaria, TB meningitis complicating HIV infection, tetanus, convulsions after a road traffic accident and rabies. He treats the first patient with quinine, the second patient with streptomycin and isoniazid, but can add rifampicin and pyrazinamide (available since the 1970s) but there is no antiretroviral therapy available in the country. The tetanus patient receives equine antitoxin and penicillin, the fourth patient phenobarbitone and the last patient is given diazepam and discharged home to die. Dr Josephine Bloggs starts in a brand new, purpose-built, state of the art hospital (financed by the Private Finance Initiative) and also sees a similar set of patients to her grandfather. The patient with unstable angina is already on nitrates, beta-blockers, enalapril, aspirin, magnesium, tirofiban and is attached to three monitors and 16 intravenous infusions. $\mathrm{He}$ is immediately rushed to the cardiac intervention suite where he has an angioplasty with stenting. $\mathrm{He}$ is discharged home $48 \mathrm{~h}$ later. The patient who has suffered a transient ischaemic attack (TIA) is urgently referred to Professor Petra Sanderman (the world's leading expert in treatment of TIAs) by internet-based TV satellite link and gives fully informed consent to enter four separate randomised trials for interventions post TIA and is sent for urgent MRA and ultrasound scans. On discovering a $65 \%$ lesion in the left internal carotid he is randomized to urgent endarterectomy, which is performed later that day. The patient with Guillain-Barré Syndrome makes a remarkable recovery following intravenous immunoglobulin, the lady with optic neuritis is prescribed beta-interferon after extensive counselling and the child with intractable temporal lobe epilepsy is sent for functional MRI, ictal SPECT and has curative temporal lobectomy performed two weeks later.

\section{GLOBAL MEDICINE IN 1952 AND 2002}

There are a few remarkable exceptions but the 


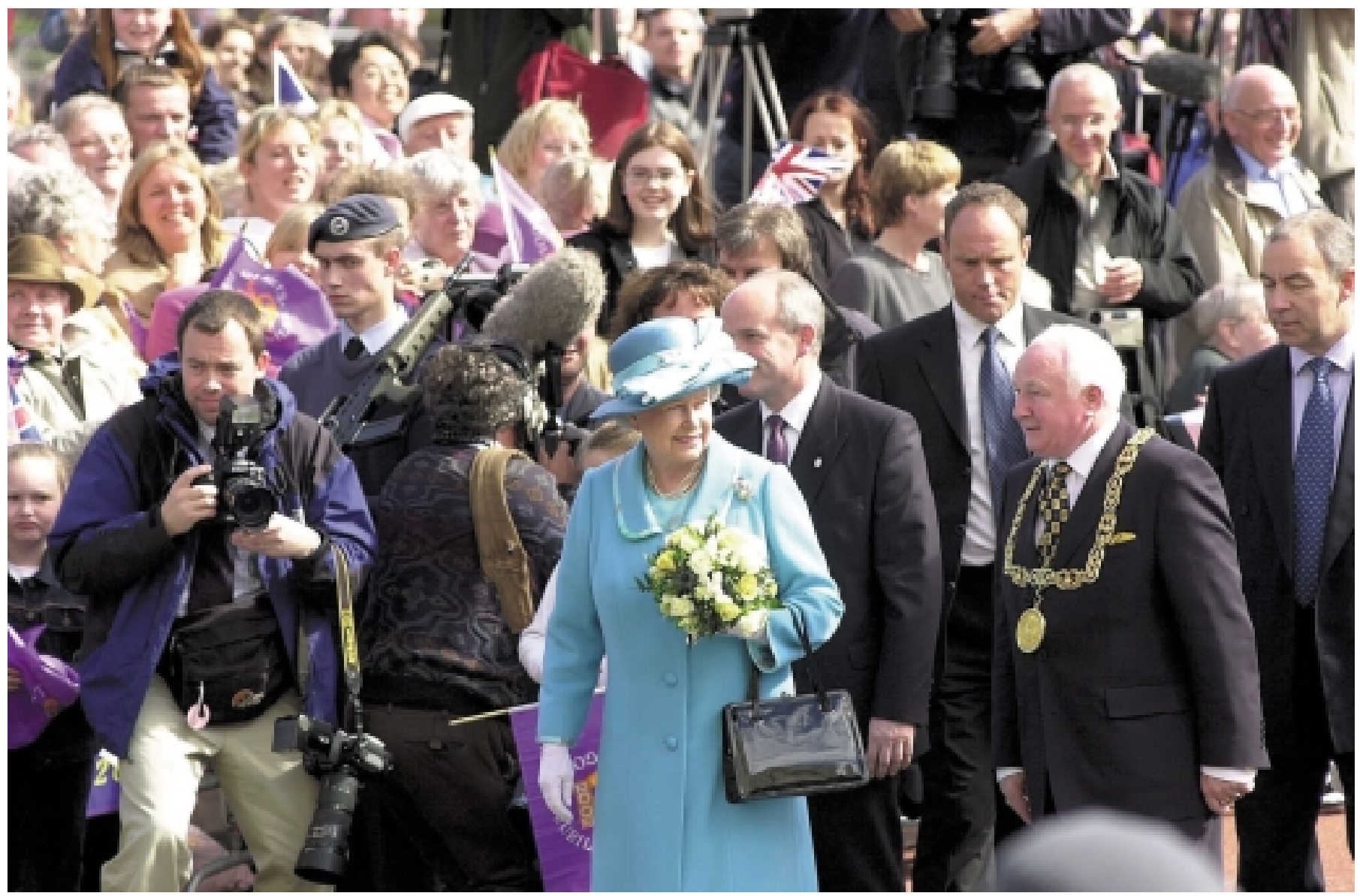

Queen Elizabeth II in 2002, her jubilee year. reality is that for the vast majority of people living in the developing world the treatment options available if they get sick have changed very little in the last 50 years. Contrast this with the situation for people living in the developed world. Quinine (first used specifically used for malaria in 1712) remains the most commonlyused drug for severe malaria. Rifampicin and pyrazinamide (both first used in the 1970s) have been added to the options for TB but treatment remains a combination of these drugs with streptomycin (1934) and isoniazid (1952). Specific therapy for tetanus has not changed in the last five decades (in fact not much in the last eight decades) and phenobarbitone remains the most commonly-used anticonvulsant despite its numerous adverse effects. Rabies still kills 100\% of people who develop symptoms. In many ways the situation is worse for Dr Mandela than it was for his grandfather. The alarming global spread of drug resistance has meant that many parasitic, bacterial and viral infections are on the verge of becoming untreatable in many parts of the world. The global devastation caused by HIV/ AIDS is only now becoming obvious. Whilst infectious diseases continue to blight the develop- ing world the future could be even worse. There are very little reliable data on the burden of disease attributable to 'diseases of the West' - i.e. stroke, diabetes, hypertension, and psychiatric illness. However, some predictions suggest that the developing and restructuring world will see an explosion in the incidence of these diseases and that they will dominate global health budgets by 2020 . The health infrastructure required to cope with these chronic diseases (in addition to existing demands) would be way beyond the means of most countries. Imagine the difficulties in running a diabetic service when there is no fridge to store insulin, or the infrastructure required to treat and support chronic mental illness. The drugs to treat infectious diseases of the developing world are already too expensive, a situation worsened by the spread of resistance. The drugs and support needed to look after someone for 30 years with hypertension, diabetes or Parkinson's disease would be impossible for a country whose annual per capita health budget is less than \$1US per annum.

But it is not all doom and gloom! Some enlightened governments, international agencies, notably the World Bank, the United Nations, 
Medicins Sans Frontieres (MSF), and a series of philanthropic donations from chief executive officers of multinationals (in addition to long standing supporters of global health care such as the Wellcome Trust and Rockefeller Institute) has raised the awareness of these issues. This may mean that for the first time there are potentially the resources and possibly the will to make a difference and address the gross imbalances in health across the globe.

What does all this have to do with the average reader of Practical Neurology? Neurological diseases have argueably an even more dramatic impact on an individual, their family and their society in a developing country than in a developed one. There is still a massive stigma associated with many of these diseases and conditions such as epilepsy, leprosy or AIDS often lead to a patient being excluded from society. If the main breadwinner of a family has encephalitis, suffers sequaelae following malaria or has a stroke this will have profound implications for the survival chances of the whole family in areas where social services and support are inadequate.

Traditionally neurology has been the preserve of the 'thinkers' rather than the 'do-ers' of medicine and (maybe unfairly) has been characterised by Ivory Towers and clinicians with 101 clever diagnoses and no treatments (apart from steroids). That has changed enormously in the last 20 years and neurologists have started to get their hands dirty at the coalface of medicine. Maybe there is now a unique opportunity for neurologists to get more involved in infectious diseases on their own patch and also in infectious and non-infectious neurological diseases in the developing world. It was encouraging to see the XVII World Congress of Neurology in 2001 devoting its first morning to infectious diseases and neurological issues affecting the developing world. It is refreshing to see this journal giving space to diseases of the developing world and I hope the publishers will make a number of subscriptions available free to institutions in Africa and beyond*.

But much more could be done. At a global level constructive pressure on pharmaceutical companies to encourage R \& D in diseases important in the developing world could bring major advances. There is almost no incentive for big pharmaceutical companies to undertake any $\mathrm{R} \& \mathrm{D}$ in diseases affecting the developing world. They stand little or no chance of recouping their development costs when their only markets are poor Asian rice farmers or children in rural Africa. They also run a significant risk of being sued by a rich traveller who gets the $1: 100000$ adverse effect when taking the drug for malaria prophylaxis on a 1 week holiday in a National Park in Kenya. But there is little point, and it has not been very successful to date, merely to attack such companies with sticks without offering some form of carrot in return. One possibility might be to offer extensions on blockbuster drug patents in the West in exchange for new drugs for malaria, TB or other diseases of the developing world. A 5 year patent extension on a new stroke prevention drug, new anticonvulsant, a treatment for dementia or even Viagra would have huge implications for a company's profit margins. This in itself might make the economic argument strong enough to persuade shareholders that it is in their interests if their companies were to undertake real $\mathrm{R} \& \mathrm{D}$ into neglected diseases in developing countries.

At a local level, Neurology Departments could offer training opportunities for international physicians and paramedics, look to recommission and pass on second hand CT and MRI scanners, undertake academic exchanges and twin themselves with similar institutions in the developing world to encourage the exchange of experience and ideas. Publishing houses could improve access to journals and other educational material ${ }^{*}$. The Internet has had a huge impact but many hospitals in the developing world don't have a reliable source of electricity let alone the web. Senior staff could be encouraged to take sabbaticals and junior staff to step off the training conveyor belt and seek broader training and research opportunities overseas. There are a large number of exciting opportunities and there is funding available for research, training, and exchange of knowledge. Further research on the pathophysiology, treatment and burden of neurological (infectious and noninfectious) diseases are urgently needed in the developing world.

In the 21st Century the current disparity in health care provision between developed and developing countries should be unacceptable. This disparity in provision is particularly true for diseases that affect the nervous system. Neurologists have to varying degrees left their ivory towers, maybe now it is time for them to engage more in global neurological issues. Dr Mandela and Dr Joseph Bloggs's great grandchildren might both then have more to offer their patients.
*Blackwell Publishing supply their journals free of charge to the 100 poorest countries through an initiative with the WHO (see http://www.healthi nternetwork.org/) 